\title{
Cystatin C or Creatinine for Detection of Stage 3 Chronic Kidney Disease in Anorexia Nervosa*
}

Pierre Delanaye ${ }^{\mathrm{a}}$, Etienne Cavalier ${ }^{\mathrm{b}}$, Régis P. Radermecker ${ }^{\mathrm{c}}$, Nicolas Paquot ${ }^{\mathrm{c}}$, Gisèle Depas ${ }^{\mathrm{d}}$, Jean-Paul Chapelle $^{\mathrm{b}}$, André J. Scheen ${ }^{\mathrm{c}}$, Jean-Marie Krzesinski ${ }^{\mathrm{a}}$

Departments of ${ }^{a}$ Nephrology, ${ }^{b}$ Clinical Chemistry, ${ }^{c}$ Diabetes, Nutrition and Metabolic Disorders and ${ }^{d}$ Nuclear Medicine, University of Liège, Liège, Belgium

\begin{abstract}
:
Background: Patients with anorexia nervosa (AN) are at a high risk of renal failure. Chronic kidney disease (CKD) is often missed in these patients because the serum creatinine is a poor marker of kidney function. We studied the utility of cystatin $C$ to detect renal failure in this population. Method: Twenty-seven AN patients were studied. Glomerular filtration rates (GFR) were measured with the chromium-51

ethylenediaminetetraacetate $\left({ }^{51} \mathrm{Cr}\right.$-EDTA) method. We compared the ability of creatinine and cystatin $\mathrm{C}$ to detect stage 3 CKD (GFR below $60 \mathrm{ml} / \mathrm{min}$ ) by ROC curve analysis. Results: In this cohort, there is no correlation between GFR and serum creatinine, but there is a significant correlation between cystatin C and GFR. By ROC analysis, the cystatin $\mathrm{C}$ concentration is better than the serum creatinine concentration for the detection of stage 3 CKD (area under the curve of 0.86 vs. $0.61, p=0.05$ ). Conclusion: Plasma cystatin $C$ is better than serum creatinine in detecting stage $3 \mathrm{CKD}$ in patients with AN.
\end{abstract}

Keywords: Anorexia nervosa $\bullet$ Glomerular filtration rate $\bullet$ Creatinine $\bullet$ Cystatin C

\section{Introduction}

Anorexia nervosa (AN) is a frequent psychiatric disorder affecting young people, with a high rate of mortality and morbidity $[1,2]$. In AN, chronic kidney disease (CKD) is not rare. More than $70 \%$ of patients with AN have had or will have a renal-related disease (acute renal failure, nephrolithiasis, edema or electrolyte disorders) [3]. Zipfel et al. [4] described a mortality rate of $16.7 \%$ and a rate of end-stage renal failure of 5.2\% in 84 women with AN, over a mean follow-up of 21 years. CKD is a silent and frequently asymptomatic disease. For these reasons, estimation of the glomerular filtration rate (GFR) and detection of decreased kidney function are essential in this population. However, impairments in kidney function are often underestimated in AN. One of the explanations may be the lack of sensitivity of serum creatinine concentration to detect decreased kidney function in these patients because of their decreased muscle mass $[5,6]$. The inability of serum creatinine to detect decreased kidney function in AN has already been reported [7-9]. We therefore considered the usefulness of cystatin $\mathrm{C}$ to detect decreased kidney function. The potential advantage of this new GFR marker in the AN population is linked to the limited relationship between cystatin $\mathrm{C}$ concentration and subject's lean body mass $[10,11]$.

\section{Method}

Between December 2002 and June 2006, we invited all anorexic patients hospitalized in the Metabolic Diseases Unit of our University Hospital to be included in the study. All patients gave their agreement to participate, and the study was approved by the ethics board of our hospital. Diagnostic criteria of AN were: refusal to maintain body weight above a minimal normal weight for age and height, intense fear of gaining weight, denial of the seriousness of current low body weight and amenorrhea. These criteria are adapted from the Diagnostic and Statistical Manual of Mental Disorders, fourth edition (DSM IV) [1]. The patients included may be considered as having severe AN because they needed hospitalization, and the majority required artificial refeeding. Additional inclusion criteria were applied, including: body mass index (BMI) below 18, and that the condition is not explainable by another disease (cancer, infection, etc.). As cystatin $\mathrm{C}$ concentrations may be influenced by steroids, we excluded patients treated by these drugs [12]. The reference method for GFR measurement was based on the plasma clearance, after a single injection bolus, of a glomerular tracer [chromium-51ethylenediaminetetraace-tate $\left({ }^{51} \mathrm{Cr}\right.$-EDTA)]. We used the 2-samples method at 120 and $240 \mathrm{~min}$ and the slopeintercept method as described by Brochner-Mortensen [13]. All GFR were measured within the first week of

\footnotetext{
${ }^{*}$ This work has been presented as an abstract at the French Society of Nephrology, Lilles, 2006.
} 
hospitalization by an experienced physician. The coefficient of variation typically observed for the GFR measurement with plasma clearance of ${ }^{51} \mathrm{Cr}$-EDTA was as low as $4 \%$ for patients with GFR over $30 \mathrm{ml} / \mathrm{min} / 1.73 \mathrm{~m}^{2}$ and $11 \%$ for those with a GFR below $30 \mathrm{ml} / \mathrm{min} / 1.73 \mathrm{~m}^{2}$. This includes the biological variation of the GFR [14]. In our institution, the reproducibility of the isotopic measurement is fairly similar ( $\pm 7 \%$ in healthy subjects, personal data). All the measurements were performed in fasting condition, from 08:00 to $12: 00$ in the morning and by the same experienced nurses. Total body irradiation with this technique was very low $(0.011 \mathrm{mSv})$ when doses were adapted to weight.

When a metabolic measurement is performed in populations with huge differences in body size such as AN (or in severe obesity), the question arises whether the measured parameter should be normalized or not for body weight or for body surface area (BSA) [15]. The GFR values were not indexed for BSA, as that indexing has been shown to be unnecessary for patients with an unusual body size $[16,17]$. Serum creatinine was measured with the kinetic rate-blanked compensated creatinine Jaffé method on Modular (Roche Diagnostics) [18], Plasma cystatin $\mathrm{C}$ was measured by a particle-enhanced nephelometric immunoassay (Dade Behring) [10,19]. A value of cystatin $\mathrm{C}$ below $1 \mathrm{mg} / \mathrm{l}$ is normal in the general population [20]. Both serum creatinine and plasma cystatin $\mathrm{C}$ were measured on the same day as GFR measurement at 08:00 in the morning in our laboratory under the supervision of an experienced clinical chemist.

Data were expressed as medians (percentile 25 to percentile 75). The plasma markers used to detect decreased kidney function were compared by correlation analysis (between GFR and the inverse of creatinine or cystatin) and the receiver operating characteristic curves (ROC curves) methods. The area under the curves was calculated to detect a stage 3 CKD defined as a GFR below $60 \mathrm{ml} / \mathrm{min}$ [21]. Statistics were performed using MedCalc ${ }^{\circledR}$ (MedCalc Software). A p value of $<0.05$ was considered as statistically significant.

Table 1: Anthropometrical, renal and biological descriptions of the population

\begin{tabular}{llll}
\hline \multicolumn{4}{l}{ Median Percentiles 25-75 Range } \\
& & & \\
\hline Age, years & 26 & $21-35$ & $15-61$ \\
Weight, kg & 44.1 & $37.1-47$ & $30.3-54.1$ \\
Height, cm & 166 & $163-173$ & $149-183$ \\
BMI & 15.8 & $13.7-16.5$ & $11.1-17.8$ \\
BSA & 1.42 & $1.29-1.5$ & $1.18-1.65$ \\
Creatinine, mg/dl & 0.85 & $0.95-1.01$ & $0.36-2.6$ \\
Cystatin C, mg/1 & 0.85 & $0.73-0.94$ & $0.6-3.03$ \\
Urea nitrogen, mg/dl & 14 & $11-18$ & $5-51$ \\
Albumin, g/dl & 4.3 & $3.9-4.5$ & $3.1-5.4$ \\
GFR, ml/min & 69.1 & $56.3-80.6$ & $13.4-134.3$ \\
\hline
\end{tabular}

\section{Results}

GFR was systematically measured in 27 patients. No patient refused to participate in the study; 25 were women and only 2 were men, as expected in AN. Anthropometric, clinical and biological data are summarized in the table 1. As expected, the population was young (30 \pm 13 years old) and very thin (mean weight: $42 \pm 7 \mathrm{~kg}$, mean BMI: $15 \pm 2$ ). All patients had a BMI under 18. As most patients with AN are young, we found no significant correlation between GFR and age $(\mathrm{r}=-0.03)$. Mean measured GFR was $68 \pm 23 \mathrm{ml} / \mathrm{min}$. Nine patients $(33 \%)$ had a GFR under $60 \mathrm{ml} / \mathrm{min}$ (stage 3 of CKD), and 16 (59\%) had a GFR between 60 and $90 \mathrm{ml} / \mathrm{min}$ (stage 2) [21]. One patient with insulin-treated diabetes had a measured GFR of $134 \mathrm{ml} / \mathrm{min}$, and might be considered as hyperfiltering.

The coefficient of correlation between measured GFR and the reciprocal of creatinine was not significant $(\mathrm{r}=0.34)$. The correlation between the reciprocal of cystatin $\mathrm{C}$ and GFR was stronger $(\mathrm{r}=0.62, \mathrm{p}<0.001$; fig. 1). To detect a GFR below $60 \mathrm{ml} / \mathrm{min}$, the area under the curve was 0.61 for creatinine and 0.86 for cystatin C. This difference was at the limit of significance $(\mathrm{p}=0.05$; fig. 2$)$. The creatinine value that gave the best sensitivity-specificity was $0.81 \mathrm{mg} / \mathrm{dl}$ (sensitivity $56 \%$, specificity $78 \%$ ). For cystatin C, the value was $0.95 \mathrm{mg} / 1$ (sensitivity $67 \%$, specificity $100 \%$ ). 
Fig. 1: Correlation between GFR and the inverse of creatinine $(a ; r=0.34, p>0.05)$ and the inverse of cystatin $C(b ; r=0.62, p<0.001)$.
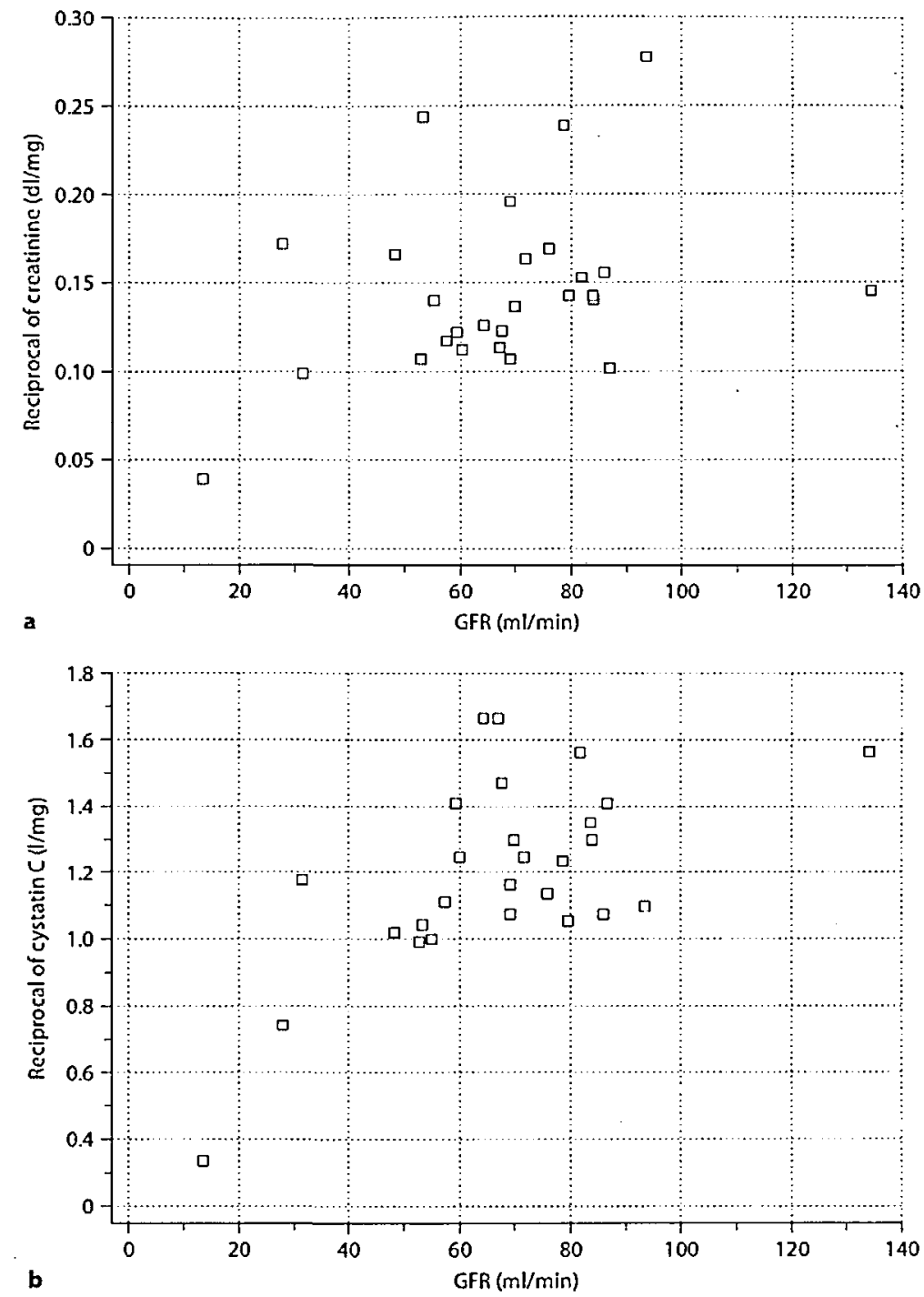

\section{Discussion}

AN-associated renal disorders are frequent and varied [3,9,22]. Acute renal failure, renal stones, chronic hypokalemia and impaired osmoregulation are classical syndromes in $\mathrm{AN}[3,9,23]$. The precise pathophysiology of decreased kidney function in AN remains largely unknown, but interstitial nephritis linked to chronic hypokalemia may have a role $[24,25]$. CKD is not rare, as up to $5 \%$ of AN patients will develop endstage renal failure after 20 years of AN [4]. These statistics are not trivial because AN affects young people who are generally not at all at risk of developing CKD. For example, in our population, 33\% of the patients have GFR under $60 \mathrm{ml} / \mathrm{min}$. Moreover, problems linked to CKD in AN are probably underestimated by physicians because classical tests to detect CKD may not be sensitive enough [5-8]. We have confirmed this in our population. Creatinine is not correlated to GFR, and the ROC curve shows a very poor area under the curve $(0.61)$ for detecting GFR under $60 \mathrm{ml} / \mathrm{min}$. This is due to the decreased muscle mass of subjects with AN, and the strong relationship between serum creatinine concentration and muscle mass [7]. Cystatin $\mathrm{C}$ is a new plasma marker of renal function [10]. This cysteine protease inhibitor of $13.3 \mathrm{kDa}$ is constantly produced by all nucleated cells of the body, is freely filtrated through the glomeruli and is neither reabsorbed nor secreted by the tubules [26,27]. It is fully catabolized in the proximal tubules [28]. Cystatin $\mathrm{C}$ has been shown to be a useful marker of GFR in several, but not all, studies of the early detection of decreased kidney function [10, 29]. It has been advocated as a marker of GFR, whose concentration is totally independent of body weight and lean body mass [11]. The advantages of this new marker over the classic serum creatinine in AN are thus theoretically high. Indeed, for the 
first time in the specific population of $\mathrm{AN}$, we have confirmed that cystatin $\mathrm{C}$ is better than creatinine for the detection of decreased kidney function defined as a GFR $<60 \mathrm{ml} / \mathrm{min}$. The correlation between cystatin $\mathrm{C}$ and GFR is strong, whereas it was absent between creatinine and GFR. Moreover, the area under the curve is statistically better for cystatin $\mathrm{C}$ than for creatinine in detecting stage $3 \mathrm{CKD}$. Our data confirm preliminary results of studies with other populations with decreased muscle mass, such as cirrhotic patients, intensive care patients and patients with a spinal cord injury [30-34].

Fig. 2: ROC curve analysis for cystatin $C$ (dashed line; area under the curve $=0.86$ ) and creatinine (bold line; area under the curve $=0.61)$ to detect stage $3 C K D(G F R$ under $60 \mathrm{ml} / \mathrm{min})$.

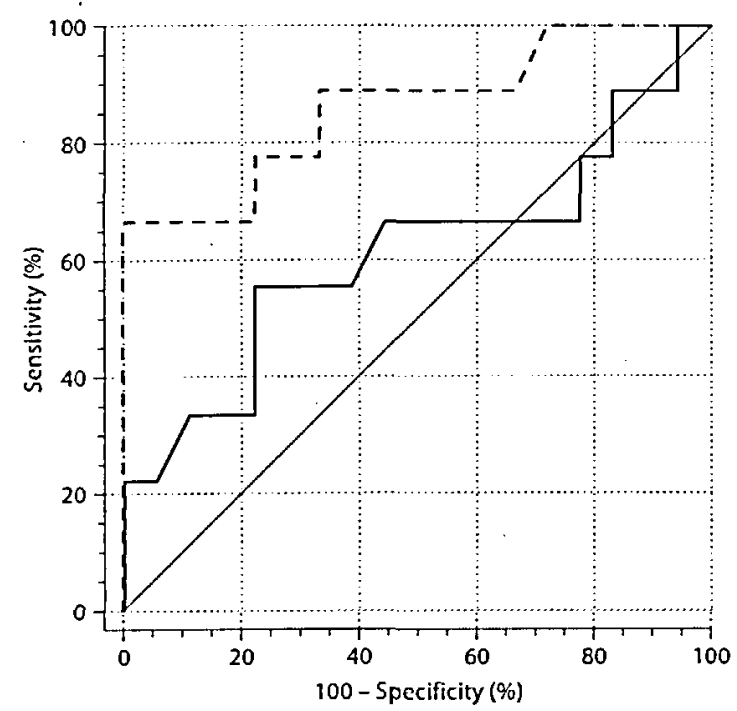

There are some limitations to our study. First of all, our sample may be considered as relatively small. Nevertheless, our population is clinically homogeneous and highly representative of severe AN patients requiring hospitalization. Furthermore, the GFR range of our population is also large (13-134 $\mathrm{ml} / \mathrm{min})$. Second, we have not indexed our GFR results for BSA, although most other studies did. We have thus defined CKD as a GFR less than $60 \mathrm{ml} / \mathrm{min}$, rather than $60 \mathrm{ml} / \mathrm{min} / 1.73 \mathrm{~m}^{2}$. Indeed, we have shown in a recent review of literature that the indexation of GFR for BSA is physiologically questionable, but has little consequences in 'normal' weight populations. Furthermore, such an indexation would have severe consequences on the final GFR in obese or AN populations. In our study, the mean absolute GFR was $68 \pm 23 \mathrm{ml} / \mathrm{min}$, although the mean indexed GFR was $80 \pm 27 \mathrm{ml} / \mathrm{min} / 1.73 \mathrm{~m}^{2}$. This rise in GFR after BSA indexation is an artifact calculation. This can be proved by reductio ad absurdum. Using indexed GFR, the sensitivity of the serum creatinine to detect 60 $\mathrm{ml} / \mathrm{min} / 1.73 \mathrm{~m}^{2}$ will be $75 \%$. The sensitivity of serum creatinine to detect kidney disease will be the same or even better in the AN population than in the general population. Due to the decreased muscular mass in AN population, this last assertion is certainly not true. Third, dysthyroidism is suspected to interfere with cystatin $\mathrm{C}$ concentrations, independently of any change in GFR [35,36]. Hypothyroidism is a known complication of AN and malnourished patients, specifically the low T3 syndrome [37]. However, hypothyroidism reduces cystatin C levels, and thus potential hypothyroidism in our patients would also reduce the sensitivity of cystatin $\mathrm{C}$ to detect CKD. Even if this potential limitation had occurred in our study, cystatin $\mathrm{C}$ would still be better than creatinine for stage $3 \mathrm{CKD}$ detection. Fourth, we cannot exclude the possibility that some patients had acute kidney injury, as our study was carried in the beginning of the hospitalization. To study the utility of cystatin $\mathrm{C}$ versus creatinine in the subgroup of acute kidney failure, and the influence on this marker of increasing or decreasing weight, a longitudinal study on a larger sample of patients would certainly be of interest. The last limitation of this study is the lack of data regarding urine albumin and urinalysis. Albuminuria is a part of the definition of stage 1 of CKD. Nevertheless, in AN, absence of albuminuria does not exclude kidney disease because kidney disease is often linked to prerenal factors (with no or low albuminuria) and/or tubular dysfunction linked to chronic hypokalemia. Then, there may be no albuminuria, but elevated urinary markers of tubular injury, like $\beta_{2}$-microglobulin.

In summary, cystatin $C$ seems superior to creatinine for the detection of decreased kidney function in a population of patients with severe AN. This fact should be confirmed in a larger population. Moreover, the better sensitivity of cystatin $\mathrm{C}$ to detect $\mathrm{CKD}$ does not mean that cystatin-C-based equations accurately estimate GFR 
in this very specific population. This point remains to be studied separately.

\section{Acknowledgments}

We want to thank Dr. Eric Cohen and Mrs. Rosalie Bonmariage for their help in the redaction of the manuscript, and Mrs Laurence Seidel for her help with the statistics. We also want to thank the nurses of the Metabolic Diseases and Nuclear Medicine units for their technical assistance.

\section{References}

1 Yager J, Andersen AE: Clinical practice. Anorexia nervosa. N Engl J Med 2005;353:1481 -1488.

2 Herzog W, Deter HC, Fiehn W, Petzold E: Medical findings and predictors of long-term physical outcome in anorexia nervosa: a prospective, 12-year follow-up study. Psychol Med 1997;27:269-279.

3 Brotman AW, Stern TA, Brotman DL: Renal disease and dysfunction in two patients with anorexia nervosa. J Clin Psychiatry 1986;47: 433-434.

4 Zipfel S, Lowe B, Reas DL, Deter HC, Herzog W: Long-term prognosis in anorexia nervosa: lessons from a 21-year follow-up study. Lancet 2000;355:721-722.

5 Perrone RD, Madias NE, Levey AS: Serum creatinine as an index of renal function: new insights into old concepts. Clin Chem 1992; 38:1933-1953.

6 Poggio ED, Nef PC, Wang X, Greene T, Van Lente F, Dennis VW, Hall PM: Performance of the Cockcroft-Gault and modification of diet in renal disease equations in estimating GFRin ill hospitalized patients. Am J Kidney Dis 2005;46:242-252.

7 Brion LP, Boeck MA, Gauthier B, Nussbaum MP, Schwartz GJ: Estimation of glomerular filtration rate in anorectic adolescents. Pediatr Nephrol 1989;3:16-21.

8 Klahr S, Tripathy K: Evaluation of renal function in malnutrition. Arch Intern Med 1966;118:322-325.

9 Aperia A, Broberger O, F'ohlin L: Renal function in anorexia nervosa. Acta Paediatr Scand 1978;67:219-224.

10 Newman DJ: Cystatin C. Ann Clin Biochem 2002;39:89-101

11 Vinge E, Lindergard B, Nilsson-Ehle P, Grubb A: Relationships among serum cystatin C, serum creatinine, lean tissue mass and glomerular filtration rate in healthy adults. Scand J Clin Lab Invest 1999;59:587-592.

12 Risch L, Huber AR: Glucocorticoids and increased serum cystatin C concentrations. Clin Chim Acta 2002;320:133-134.

13 Brochner-Mortensen J: A simple method for the determination of glomerular filtration rate. Scand J Clin Lab Invest 1972;30:271-274.

14 Brochner-Mortensen J, Rodbro P: Optimum time of blood sampling for determination of glomerular filtration rate by single-injection [51Cr]EDTA plasma clearance. Scand J Clin Lab Invest 1976;36:795-800.

15 Castillo MJ, Scheen AJ, Jandrain B, Lefebvre PJ: Relationships between metabolic clearance rate of insulin and body mass index in a female population ranging from anorexia nervosa to severe obesity. Int J Obes Relat Metab Disord 1994;18:47-53.

16 Delanaye P, Radermecker RP, Rorive M, De-pas G, Krzesinski JM: Indexing glomerular filtration rate for body surface area in obese patients is misleading: concept and example. Nephrol Dial Transplant 2005:20:2024-2028.

17 Turner ST, Reilly SL: Fallacy of indexing renal and systemic hemodynamic measurements for body surface area. Am I Physiol 1995;268:R978-R988.

18 Mazzachi BC, Peake MJ, Ehrhardt V: Reference range and method comparison studies for enzymatic and Jaffe creatinine assays in plasma and serum and early morning urine. Clin Lab 2000;46:53-55.

19 Stowe H, Lawrence D, Newman DJ, Lamb EJ: Analytical performance of a particle-enhanced nephelometric immunoassay for serum cystatin C using rate analysis. Clin Chem 2001;47:1482-1485.

20 Galteau MM, Guyon M, Gueguen R, Siest G: Determination of serum cystatin C: biological variation and reference values. Clin Chem Lab Med 2001;39:850-857.

21 National Kidney Foundation: K/DOQI clinical practice guidelines for chronic kidney disease: evaluation, classification, and stratification. Am J Kidney Dis 2002;39:S1-S266. 
Published in: Nephron. Clinical Practice (2008), vol.110, iss.3, pp.158-163

Status: Postprint (Author's version)

22 Palla B, Litt IF: Medical complications of eating disorders in adolescents. Pediatrics 1988; 81:613-623.

23 Evrard F, da Cunha MP, Lambert M, Devuyst O: Impaired osmoregulation in anorexia nervosa: a case-control study. Nephrol Dial Transplant 2004;19:3034-3039.

24 Arimura Y, Tanaka H, Yoshida T, Shinozaki M, Yanagida T, Ando T, Hirakata H, Fujishima M: Anorexia nervosa: an important cause of chronic tubulointerstitial nephropathy. Nephrol Dial Transplant 1999;14:957-959.

25 Schwartz WB, Relman AS: Effects of electrolyte disorders on renal structure and function. N Engl J Med 1967;276:383-389.

26 Abrahamson M, Olafsson I, Palsdottir A, Ulvsback M, Lundwall A, Jensson O, Grubb A: Structure and expression of the human cystatin C gene. Biochem J 1990;268:287-294.

27 Tenstad O, Roald AB, Grubb A, Aukland K: Renal handling of radiolabelled human cystatin C in the rat. Scand J Clin Lab Invest 1996;56:409-414.

28 Jacobsson B, Lignelid H, Bergerheim US: Transthyretin and cystatin C are catabolized in proximal tubular epithelial cells and the proteins are not useful as markers for renal cell carcinomas. Histopathology 1995;26: 559-564.

29 Dharnidharka VR, Kwon C, Stevens G: Serum cystatin C is superior to serum creatinine as a marker of kidney function: a metaanalysis. Am J Kidney Dis 2002;40:221-226.

30 Delanaye P, Lambermont B, Chapelle JP, Gielen J, Gerard P, Rorive G: Plasmatic cystatin C for the estimation of glomerular filtration rate in intensive care units. Intensive Care Med 2004;30:980-983.

31 Demirtas S, Bozbas A, Akbay A, Yavuz Y, Karaca L: Diagnostic value of serum cystatin C for evaluation of hepatorenal syndrome. Clin Chim Acta 2001;311:81-89.

32 Randers E, Ivarsen P, Erlandsen EJ, Hansen EF, Aagaard NK, Bendtsen F, Vilstrup H: Plasma cystatin C as a marker of renal function in patients with liver cirrhosis. Scand J Clin Lab Invest 2002;62:129-134.

33 Thomassen SA, Johannesen IL, Erlandsen EJ, Abrahamsen J, Randers E: Serum cystatin C as a marker of the renal function in patients with spinal cord injury. Spinal Cord 2002:40:524-528.

34 Gerbes AL, Gulberg V, Bilzer M, Vogeser M: Evaluation of serum cystatin C concentration as a marker of renal function in patients with cirrhosis of the liver. Gut 2002;50:106-110.

35 den Hollander JG, Wulkan RW, Mantel MJ, Berghout A: Is cystatin C a marker of glomerular filtration rate in thyroid dysfunction? Clin Chem 2003;49:1558-1559.

36 Jayagopal V, Keevil BG, Atkin SL, Jennings PE, Kilpatrick ES: Paradoxical changes in cystatin C and serum creatinine in patients with hypo-and hyperthyroidism. Clin Chem 2003;49:680-681.

37 Onur S, Haas V, Bosy-Westphal A, Hauer M, Paul T, Nutzinger D, Klein H, Muller MJ: L-tri-iodothyronine is a major determinant of resting energy expenditure in underweight patients with anorexia nervosa and during weight gain. Eur J Endocrinol 2005:152:179-184. 